\title{
The Influence of Education and Home Environment on the Cognitive Outcomes of Preschool Children in Germany
}

\author{
Nicole Biedinger \\ Mannheim Centre for European Social Research (MZES), University of Mannheim, 68131 Mannheim, Germany \\ Correspondence should be addressed to Nicole Biedinger, nicole.biedinger@mzes.uni-mannheim.de
}

Received 18 August 2010; Revised 18 November 2010; Accepted 12 January 2011

Academic Editor: Masha Gartstein

Copyright () 2011 Nicole Biedinger. This is an open access article distributed under the Creative Commons Attribution License, which permits unrestricted use, distribution, and reproduction in any medium, provided the original work is properly cited.

Educational inequality is a well-established topic among the scientific community in Western countries. Major individual differences emerge well before children arrive at school. Therefore the following analysis deals with the explanation of early differences in cognitive outcomes. However, there is not much research done in Germany. The main question is if the strong effect of the educational background and the home environment on their outcomes and on the improvement exists as well. To test this, data of the project "Preschool Education and Educational Careers among Migrant Children" was used. The results of structural equation models confirm that the home environment and the education of the parents are important for children's outcomes at the age of 3 to 4 . In addition both factors also play a major role for the explanation of the improvement of the cognitive abilities. The results show that in Germany the home environment and parental education are important predictors of cognitive abilities. As a main result the study shows that it is very important to control for earlier abilities of the children and to encourage low educated parents to be active with their children, since in that way they can compensate for their lower educational background.

\section{Introduction}

Educational inequality is a well-established topic among the scientific community in Western countries. Especially since the "Program for International Student Assessment (PISA)" was conducted and results in most countries exposed huge drawbacks on the part of social disadvantaged pupils, research efforts have even been intensified. In particular, the early childhood years are increasingly seen as a period crucial to the growth and consolidation of important skills necessary for successful school transition and later academic functioning.

Major individual differences emerge well before children arrive at school. Therefore the following analysis deals with the explanation of early differences in cognitive outcomes. Current explanations of inequality stress the influence of cultural and human capital. The cultural capital of parents influences the home environment and activities between parents and their children $[1,2]$. An analogous mechanism holds true for the case of human capital: if parents are highly educated, the probability rises that their children will also be highly educated. It is assumed that it is easier for highly educated parents to help and stimulate their children. Conclusively, a child's chance of positive cognitive outcomes depends on the (educational) resources of its parents and their home environment. Even though the disadvantages of social groups might still be quite small at early ages, in the long run, the accumulation process produces great differences.

In this study, I will analyse early educational inequality using the example of cognitive outcomes. Cognitive outcomes themselves are one of those abilities that are necessary in order to start school. Although family processes are stressed so far, the main research deals with the influence of preschool or child care programs on early skills necessary for educational success. The main question for this paper is whether there really exists the assumed strong effect of the family background and the home environment on outcomes and for improvements for preschool children living in Germany. This is of special interest, since the preschool system in Germany differs from the American system, so that results from the USA are not transferable. 
The German preschool system is very homogeneous. The typical, and often only, chargeable preschool establishment available for children from age 3 until they enter school is the so-called 'Kindergarten.' The Kindergarten provides care, but for the last 15 years the strengthening of the educational mission is claimed as well. However, even today, there is no systematic link to schools. Kindergarten is usually operated by the community or by nonprofit organizations. The quality is generally regulated at the state level, with a focus on structural features such as staff-to-child ratios, group size, or building standards. Although in Germany, attendance at preschool is not mandatory, preschool nonetheless is intended to prepare children for school. In Germany, attending preschool for at least 1 year before school begins has become the norm for young children. But differences in attendance rates still persist. The largest differences are the following.

(1) Costs: the "Kindergarten" in Germany is very cheap (in some federal states even free of charge).

(2) Care: in Germany the main focus of kindergarten is on caring for children. In contrast to this the American kindergarten, is rather similar to school (learning of numbers, letters, etc.).

(3) Heterogeneity: the preschool system in Germany is very homogeneous; there is just "Kindergarten," where in other countries there exist very different types of child care (e.g., preschool, nursery school, kindergarten, child care, etc.)

However, it is hypothesized that the home environment and family background are very important for the cognitive abilities and for their improvement (cf. $[3,4])$. The following section will give an overview of the state-of-the-art and give some theoretical arguments for the explanatory power of the educational background and the home environment for early cognitive abilities. Additionally, the influence of prior outcomes as one option to measure the improvement of abilities will be discussed. Section 3 will introduce the data and method, followed by the results (Section 3.4). The last section sums up the results and discusses some methodological problems.

\section{Influence of Social Background and Home Environment on Children's Cognitive Abilities}

A central concern of social stratification research has been the intergenerational transmission of social inequality and the mechanism that leads to this transmission. In particular, there have been a large number of studies that have examined the linkages between families socioeconomic conditions and educational outcomes of their offspring. Fergusson et al. [5] assume four different explanations for the transmission of social inequality. They argue that this could be explained firstly by the economic situation of the family, secondly by socialisation processes, thirdly by biological reasons, and fourthly through educational institutions. Gaps in cognitive skills arise before children go to school, so the fourth explanation is not suitable for explaining very early developmental outcomes. To explain these outcomes I will focus on the explanations number one and two, since I cannot control for biological aspects with the data. First, families' economic situation is determined by their educational background, so parental education seems to be the most important factor to explain developmental outcomes. Second, the type of socialisation seems to be very important, and I assume this can be measured through the interaction within the families and their home environment.

In sum, it is assumed that educational success depends on children's abilities in preschool age. The acquisition of these abilities is determined thereby particularly by the family. The family's influence is measured as the effect of education of the care taker and by their home environment. The home environment is determined by the availability of stimulating materials (e.g., books, toys, helping teacher), but also through joint time (e.g., attending the library or the museum) (e.g., see [6]). However the inner-family interaction is not a direct consequence of the economic and educational resources of the family. Home-interaction is also influenced by noneconomic and noneducational aspects of these families (e.g., cultural background, aspirations, etc.).

Previous research has shown that there exist developmental differences of children from different social classes (e.g., see [7]). Feinstein [8] finds with data of the British Cohort Study that children are already stratified by social class in a standard test of intellectual and personal development at 22 months and this stratification even becomes more extreme in later years. He also finds that having a low rank at an early age does not matter greatly for a child's future position in the distribution unless the child is low SES as well. As a result he argues that controlling for SES, the preschool score, still matters. Nonetheless, as well as influencing early ability, family background plays a tremendously important role in determining the continued ability development of UK children. These differences even rise through the years [9]. He concludes that this leads to a strong advantage of early intervention programs. However, these programs are supposed to be very expensive. Also within newer datasets like the Millennium Cohort Study (MCS) George et al. [10] state that children with the most educated parents (who had degree-level or above qualifications) are on average about 12 months ahead of those with the least educated parents (who had no qualifications): children in higher income families achieved better scores. The limited access of families of lower SES to economic resources sets up conditions and creates barriers that limit the educational achievements of children born in such families [11-13]. Overall, the results show a marked difference in children from advantaged versus disadvantaged backgrounds and that inequalities in cognitive achievements are already established in early years.

Besides these, the environment within the family offers special learning conditions for the child and can thus positively improve the development (see $[14,15]$ ). Especially for young children the home environment is very important $[16,17]$, and concrete activities, as, for example, reading aloud are very stimulating [18-20]. So far it could be shown 
that a stimulating environment can affect the development even stronger than the socioeconomic origin [21]. Since disadvantaged children often suffer of worse home environments, a lot of federal programs try to compensate for disadvantages in home environments, for example, Head Start in the United States or Sure Start in the United Kingdom. These are designed to level the playing field at or shortly before school entry, for children from less privileged backgrounds (see [22-24]). However, there are still some unexplained mechanisms, especially for very young children in Europe.

Huge amounts of research explaining early cognitive outcomes do not consider the cognitive development of the child prior to the dependent outcome (e.g., $[25,26]$ ). However, a lot of studies have shown that early abilities or behaviour is important for later outcomes (see results of a meta-analysis of cross-time relations of academic/cognitive and social/behavioural assessments from preschool to second grade [27]). The missing research considering prior abilities in Germany might be due to data restriction or because the measurement of early abilities is very difficult. Fortunately, there exists some international research, which controls for prior achievements (e.g., [28, 29]). Reynolds and Temple [30] find that even after controlling for prior achievements special programs like the Chicago Child-Parent Center and Expansion Program can influence the reading and math achievement of 7 th graders. They also control for some social background variables, and they find that the education of the parent has a significant influence on the achievement, while the family income has not. Using a quite small Swedish dataset, Broberg et al. [31] also find that earlier measures of cognitive abilities are the best predictor of cognitive performance at 8 years of age. Moreover they find that the measure of home environment, which predicts verbal abilities in earlier phases, is no predictor for children who are in second grade any longer. They assume that this unexpected finding might be explained by niche-picking, where the growing child chooses her or his own environment by itself. Yeung and Pfeiffer [32] also recently showed that it is important to control for earlier abilities when analysing the black-white gap.

This paper analyses the influence of the home environment and parental education on cognitive ability. The collected dataset is unique for Germany and gives the outstanding opportunity to analyse this question for preschool children. First, the following analysis will test the assumption that the education of the parents and their home environment (measured through joint activities) influence the cognitive outcomes of the child. To test this, I use a sample of 3-to-5-year-old German children. Second, I will test the assumption that both factors are also important for the improvement of cognitive abilities. This will be done by controlling for an earlier outcome.

\section{Data}

The data for the empirical analysis is part of the project "Preschool Education and Educational Careers among
Migrant Children." German and Turkish families with preschool children were randomly selected from data of registration offices in 30 German cities and communities (about 65 percent of the families participated). A letter describing the study was sent to the families (Turkish families received this letter in German and in Turkish). Thereafter, interviewers contacted the families to arrange a date for the interview at their homes. After the computer assisted personal parent interview with the person spending the most time with the child (95 percent were the mother), the standardized developmental test "Kaufman Assessment Battery for Children" (K-ABC) was conducted with the child (see [33]; German version by [34]). Altogether, we surveyed 625 Turkish and 610 German families in the first half of the year 2007 (also 46 families with other ethnic origin were interviewed, but these will be dropped in the further analysis). This procedure was done twice, with a time span of about 12 months in-between. After deleting the cases with missing information at the model variables, 1009 cases remain for the analyses. The operationalisation of the variables is presented next.

3.1. Cognition. As a measure of the children's cognitive development, I use three subtests of the German version of the "Kaufman Assessment Battery for Children" (K-ABC). All of these variables are supposed to measure the cognitive ability of the children:

(i) magic window: identifying a picture through a slit;

(ii) face recognition: a picture with one person was shown, after that the child has to recognize this person out of a group;

(iii) gestalt closure: examinee looks at incomplete "inkblot" drawing and identifies pictures.

The raw scores of the correct answers of all subtests of the child load on an unobserved exogenous variable, which I will call cognition ( $z$-score). This was done for wave one (t1) and wave two (t2) (eigenvalue wave 1: 1.05, wave 2: 0.98 ). The reliability is marginal, but still useful (wave 1: Cronbach's alpha $=0.65$; wave 2 : Cronbach's alpha $=0.63$ ). If a child missed to do one subtest out of these three, I decided to impute the mean result of children of the same age (in months). This was done with no special software package, just by assuming that the mean of children of the same age would be a good proxy for the result of this child with the missing value. For the first wave 77 values were imputed, for the second wave just 26 values have been added. This does not change the results of the following analysis, but fewer observations are lost.

3.2. Years of Parental Education. They are the years of education of the parent who is mainly responsible for the child. 
3.3. Home Environment. The parents were asked about the frequency of the following activities using a 7-point scale ranging from 1 "never" to 7 "daily":

(i) telling stories to child;

(ii) reading books aloud to child;

(iii) playing cards or board games with child.

The given answers of the parents load on an unobserved exogenous variable, which I will call home environment (eigenvalue $=0.79$, Cronbach's alpha $=0.53)$. This variable measures the activities at the first wave, because later activities might be rather similar and will not be able to influence earlier outcomes of the child.

\subsection{Control Variables}

(i) Ethnic origin: children are considered as having a Turkish migration background if at least one of their parents or grandparents was born in Turkey.

(ii) Age of the child in months at wave one.

(iii) Time span between the two measurements.

(iv) Duration of preschool attendance: because some children started preschool after the first measurement two different variables are considered, one variable with the duration up to the measurement of the first wave and another variable with the duration up to the second measurement.

\section{Method}

To test my hypothesis of how parents' education and the home environment influence children's cognitive achievement, I used the Amos 18.0.0 program for structural equation modelling (SEM) (see [35]). I used this method, because OLS linear regression would produce misleading results. The assumption that errors are uncorrelated is not met, because the residuum of the dependent and independent variable is correlated. This problem can be solved by using SEM. (Some alternative methods like cross-lagged panel models, fixed effect models, or hierarchical linear regression models were also regarded, but are not appropriate, because our panel consists only of two waves and the model covers some important time-constant variables, which should be considered. These aspects contradict using these methods.) An additional advantage of using structural equation modelling techniques to test complex models is that it allows one to account for measurement error, correlated measurement error, and nonrecursive pathways [36]. Structural equation modelling is particularly suited to test mediators because it permits the simultaneous estimation of direct and indirect paths. It analyzes each path after the effects of all other paths are accounted for and provides fit indices that facilitate comparison of saturated and parsimonious models using maximum likelihood estimates [37].

The fit of the model was evaluated against the following criteria: chi-square and the degree of freedom $\left(\chi^{2} / d f\right)$, the

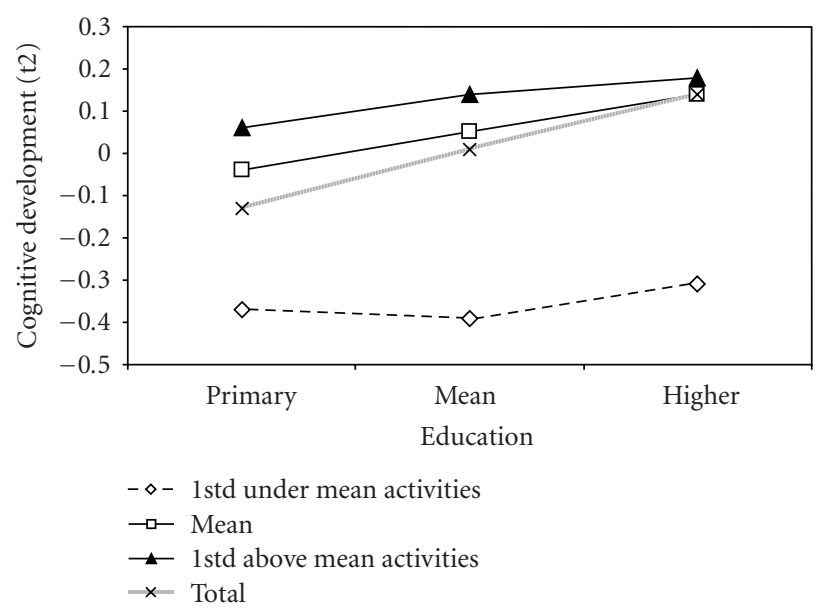

Figure 1: Cognitive outcomes by education and home environment. Note. Cognitive outcomes by education of the caretaker and activities. Own calculations with data of the project "Preschool Education and Educational Careers among Migrant Children."

comparative fit index (CFI), an incremental fit measurement (NFI) and the root mean square error of approximation (RMSEA). The chi-square index assesses the degree of nonfit between the estimated and observed covariance matrices. In general, chi-square ratios $\left(\chi^{2} / d f\right)$ between 1 and 3 indicate good model fit. With a big sample size of 200 or more respondents, the chi-square test often indicates a significant probability [36]. The CFI is a relative fit measure, which also takes the degrees of freedom into consideration. Models are considered a good fit if CFIs are greater than .90. The NFI is an incremental fit measure, which increases with parameters and sample size. The models are considered a good fit if NFI is greater than .95. The RMSEA is a measure of fit and takes into account the error approximation in the population. A value of .05 or lower is an indication of adequate or good fit [38-40].

The results of the SEM will mainly focus on the direct effects of independent variables on a dependent variable. Indirect effects are those where an independent variable influence a dependent variable via a mediating variable. The sum of all direct and indirect effects is the so-called total effect (for details see [40]).

\section{Descriptives}

Figure 1 shows descriptively that the cognitive outcomes ( $\mathrm{t} 2$ ) of the child are determined by the education of the caretaker and their home environment. The figure demonstrates that-without controlling for the home environment-the cognitive outcomes rise if the education of the caretaker rises (total line). After controlling for the activities at home the pattern is much more differentiated. Children who have a home environment one standard deviation below the mean have an inferior cognitive score than children who have a mean or above the mean home environment. In sum education and home environment have a huge impact on the cognitive outcomes, and both variables are important. 
TABLE 1: Descriptive statistics of all variables.

\begin{tabular}{|c|c|c|c|c|c|c|c|c|}
\hline \multirow{2}{*}{\multicolumn{2}{|c|}{ Description and range (min-max) }} & & & \multicolumn{2}{|c|}{ Cognition (t1) $\downarrow$} & \multicolumn{2}{|c|}{ Cognition $(\mathrm{t} 1) \uparrow$} & \multirow[b]{2}{*}{$t$-test } \\
\hline & & \multicolumn{2}{|c|}{ Mean SE } & \multicolumn{2}{|c|}{ Mean SE } & \multicolumn{2}{|c|}{ Mean SE } & \\
\hline \multicolumn{9}{|l|}{ Cognition (t1) } \\
\hline Magic window & $(0-15)$ & 7.43 & $(3.39)$ & & & & & \\
\hline Face recognition & $(0-15)$ & 7.20 & $(2.95)$ & & & & & \\
\hline Gestalt closure & $(0-20)$ & 5.43 & $(3.04)$ & & & & & \\
\hline \multicolumn{9}{|l|}{ Cognition (t2) } \\
\hline Magic window & $(0-15)$ & 10.63 & $(2.59)$ & 9.59 & $(2.83)$ & 11.57 & $(1.92)$ & $*$ \\
\hline Face recognition & $(0-15)$ & 10.44 & $(2.58)$ & 10.04 & $(2.82)$ & 10.80 & $(2.28)$ & $*$ \\
\hline Gestalt closure & $(0-23)$ & 10.27 & $(3.61)$ & 8.73 & $(3.54)$ & 11.65 & $(3.07)$ & $*$ \\
\hline \multicolumn{9}{|l|}{ Home environment $(\mathrm{t} 1)$} \\
\hline Story telling & $(1-7)$ & 5.21 & $(2.07)$ & 4.79 & $(2.20)$ & 5.59 & $(1.86)$ & $*$ \\
\hline Reading aloud & $(1-7)$ & 5.55 & $(1.99)$ & 4.92 & $(2.21)$ & 6.11 & $(1.57)$ & $*$ \\
\hline Playing cards & $(1-7)$ & 4.92 & $(1.87)$ & 4.68 & $(2.05)$ & 5.14 & $(1.66)$ & $*$ \\
\hline Years of parental education & $(0-13)$ & 10.03 & $(2.54)$ & 9.30 & $(2.70)$ & 10.70 & $(2.19)$ & $*$ \\
\hline Ratio of Turkish & $(0-1)$ & 0.49 & & 0.64 & & 0.36 & & * \\
\hline Age (t1) & $(34-51)$ & 42.13 & $(3.79)$ & 40.79 & $(3.71)$ & 43.33 & $(3.44)$ & $*$ \\
\hline Age (t2) & $(45-64)$ & 54.76 & $(4.03)$ & 53.40 & $(4.02)$ & 55.98 & $(3.64)$ & $*$ \\
\hline Preschool attendance (t2) & $(0-62)$ & 17.97 & $(7.40)$ & 16.45 & $(6.98)$ & 19.33 & $(7.51)$ & * \\
\hline Time span (t2-t1) & $(9-17)$ & 12.63 & $(1.39)$ & 12.61 & $(1.34)$ & 12.65 & $(1.43)$ & \\
\hline $\mathrm{N}$ & & \multicolumn{2}{|c|}{1009} & \multicolumn{2}{|c|}{477} & \multicolumn{2}{|c|}{532} & \\
\hline
\end{tabular}

Note. Own calculations with data of the project "Preschool Education and Educational Careers among Migrant Children". Cognition (t1) $\downarrow$ is a subsample of all children who have below the mean Cognition ( $\mathrm{t} 1$ ). Cognition ( $\mathrm{t} 1) \uparrow$ contains all children scores above the mean. The results of a two-group mean comparison test. * Significant $P \leq .05$.

TABLE 2: Standardized direct, indirect, and total effects on cognition.

\begin{tabular}{|c|c|c|c|}
\hline & & Model 1 (Figure 2) & Model 2 (Figure 3) \\
\hline & & Standardized direct effects & \\
\hline Education & $\rightarrow$ Cognition $(\mathrm{t} 1)$ & & $0.131^{* *}$ \\
\hline Home Environment & $\rightarrow$ Cognition $(\mathrm{t} 1)$ & & $0.318^{* *}$ \\
\hline Education & $\rightarrow$ Cognition $(\mathrm{t} 2)$ & $0.119^{*}$ & 0.020 \\
\hline \multirow[t]{2}{*}{ Home Environment } & $\rightarrow$ Cognition $(\mathrm{t} 2)$ & $0.181^{* *}$ & $-0.036^{+}$ \\
\hline & & Standardized indirect effects & \\
\hline Education & $\rightarrow$ Cognition $(\mathrm{t} 1)$ & & 0.144 \\
\hline Home Environment & $\rightarrow$ Cognition $(\mathrm{t} 1)$ & & \\
\hline Education & $\rightarrow$ Cognition $(\mathrm{t} 2)$ & 0.079 & 0.166 \\
\hline \multirow[t]{2}{*}{ Home Environment } & $\rightarrow$ Cognition $(\mathrm{t} 2)$ & & 0.211 \\
\hline & & Standardized total effects & \\
\hline Education & $\rightarrow$ Cognition $(\mathrm{t} 1)$ & & $0.271^{* *}$ \\
\hline Home Environment & $\rightarrow$ Cognition $(\mathrm{t} 1)$ & & $0.318^{* *}$ \\
\hline Education & $\rightarrow$ Cognition $(\mathrm{t} 2)$ & $0.198^{* *}$ & $0.186^{*}$ \\
\hline Home Environment & $\rightarrow$ Cognition (t2) & $0.181^{* *}$ & $0.176^{* *}$ \\
\hline
\end{tabular}

Note. Own calculations with data of the project "Preschool Education and Educational Careers among Migrant Children."

${ }^{*}$ Significant ${ }^{+} P<.10 .{ }^{*} P<.05 .{ }^{*} P<.01$.

Table 1 shows the means and standard deviations for all variables. The second column shows the mean of all cases. As intended with $\mathrm{K}-\mathrm{ABC}$ the measurement of the cognitive abilities is normally distributed with a mean around seven for the first two subtests. The mean of gestalt closure is a bit lower than expected. Between the two waves the children improved within all tests. The improvement of gestalt closure is biggest. The independent variables also show that there is variance in the activities at home, although most of the families quite often tell stories, read aloud, or play with their children. In the mean the care takers have 10 years of education, and half of them have a Turkish origin. During the first wave the children were about 42 months old and during the second wave about 54 months, which means that between 
TABLE 3: Measurement Model of the SEM presented in Figure 2.

\begin{tabular}{|c|c|c|c|c|}
\hline $\begin{array}{l}\text { Dependent variable } \\
\text { effects on Indicators }\end{array}$ & $\leftarrow$ Independent variable & Unstandardized coefficient & SE & $P$ \\
\hline Home environment & $\leftarrow$ Education & 0.164 & 0.026 & $* * *$ \\
\hline Preschool (t2) & $\leftarrow$ Ethnic origin & -2.213 & 0.499 & $* * *$ \\
\hline Preschool (t2) & $\leftarrow$ Education & 0.065 & 0.098 & \\
\hline Cognition (t2) & $\leftarrow$ Home environment & 0.211 & 0.057 & $* * *$ \\
\hline Cognition (t2) & $\leftarrow$ Education & 0.053 & 0.021 & $*$ \\
\hline Cognition (t2) & $\leftarrow$ Preschool (t2) & 0.009 & 0.006 & \\
\hline Cognition (t2) & $\leftarrow$ Age $(\mathrm{t} 2)$ & 0.105 & 0.012 & $* * *$ \\
\hline Magic window (t2) & $\leftarrow$ Cognition $(\mathrm{t} 2)$ & 1.449 & 0.081 & $* * *$ \\
\hline Face recognition (t2) & $\leftarrow$ Cognition $(\mathrm{t} 2)$ & 1.000 & & \\
\hline Gestalt closure (t2) & $\leftarrow$ Cognition $(\mathrm{t} 2)$ & 2.377 & 0.125 & $* * *$ \\
\hline Story telling & $\leftarrow$ Home environment & 1.000 & & \\
\hline Reading aloud & $\leftarrow$ Home environment & 1.500 & 0.229 & $* * *$ \\
\hline Playing games & $\leftarrow$ Home environment & 0.235 & 0.073 & $* *$ \\
\hline Magic window (t2) & $\leftarrow$ Ethnic origin & -0.773 & 0.174 & $* * *$ \\
\hline Face recognition (t2) & $\leftarrow$ Ethnic origin & 1.679 & 0.160 & $* * *$ \\
\hline Gestalt closure (t2) & $\leftarrow$ Ethnic origin & -0.015 & 0.251 & \\
\hline Playing games & $\leftarrow$ Ethnic origin & -0.352 & 0.122 & $* *$ \\
\hline Story telling & $\leftarrow$ Ethnic origin & -0.781 & 0.143 & $* * *$ \\
\hline Reading aloud & $\leftarrow$ Ethnic origin & -1.495 & 0.121 & $* * *$ \\
\hline Playing games & $\leftarrow$ Age $(\mathrm{t} 2)$ & 0.051 & 0.014 & $* * *$ \\
\hline Reading aloud & $\leftarrow$ Age $(\mathrm{t} 2)$ & 0.013 & 0.012 & \\
\hline Story telling & $\leftarrow$ Age $(\mathrm{t} 2)$ & 0.020 & 0.015 & \\
\hline
\end{tabular}

*** Significant with $P \leq .001$. ${ }^{* *}$ Significant with $P \leq .01$. ${ }^{*}$ Significant with $P \leq .05$.

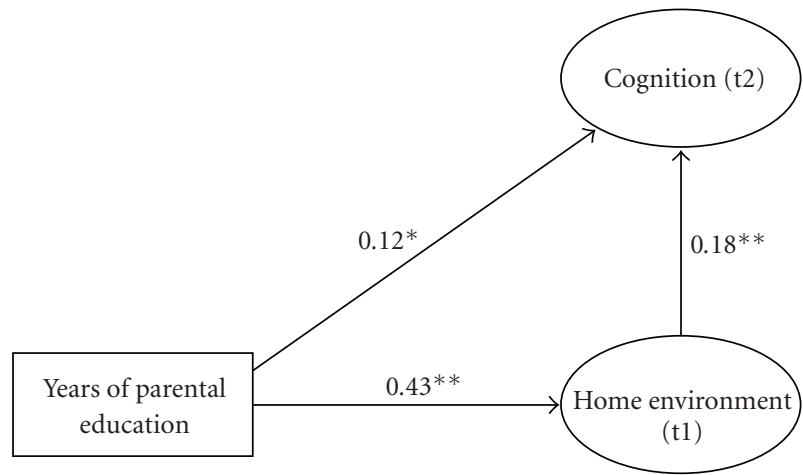

Figure 2: Influence of family and home environment on cognitive outcomes (t2). Note. Model predicting cognitive outcomes. Own calculations with data of the project "Preschool Education and Educational Careers among Migrant Children," standardized estimates under control of ethnic origin, age (t2), and preschool attendance. Model fit statistics: $N=1009 ; \chi^{2}=46.33 / d f=22$; chi-square ratio $=2,11$; CFI $=.99 ; \mathrm{NFI}=0.98 ; \mathrm{RMSEA}=0.03 ;{ }^{+} P<.10 .{ }^{*} P<.05$. $* * P<.01$.

the measurements passes about 12 months. The children attend preschool at the second wave for about 18 months.

Columns three and four of Table 1 report the means and standard deviations of the children with cognitive ability below and above the mean at the first wave. Most of

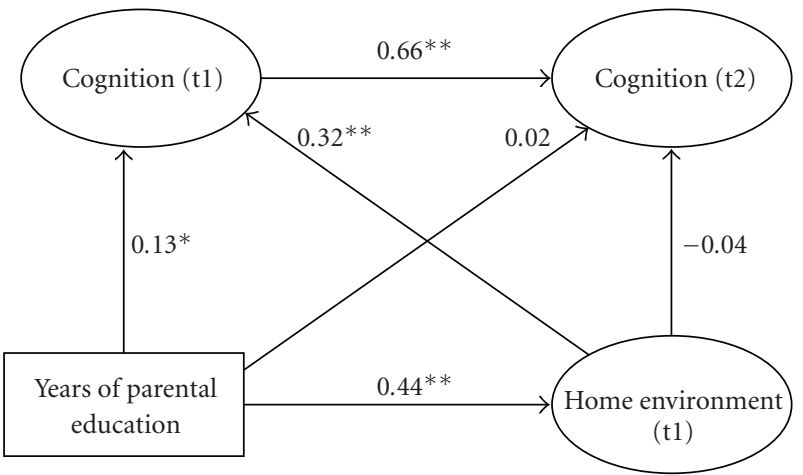

Figure 3: Influence of family and home environment on cognitive improvement. Note. Model predicting cognitive outcomes. Own calculations with data of the project "Preschool Education and Educational Careers among Migrant Children" standardized estimates under control of ethnic origin, age (t1), time span, and preschool attendance. Model fit statistics: $N=1009 ; \chi^{2}=93.18 / d f=53$; chisquare ratio $=1.76 ; \mathrm{CFI}=.99 ; \mathrm{NFI}=.97$; $\mathrm{RMSEA}=0.03 .{ }^{+} P<.10$. ${ }^{*} P<.05$. ${ }^{* *} P<.01$.

the variables significantly differ between these subgroups. Unsurprisingly, the children with better cognitive scores at wave one are about 3 months older, but they also have more active home environments, their parents exceeding year of education, and there are less families with ethnic origin. To 
TABLe 4: Measurement model of the SEM presented in Figure 3.

\begin{tabular}{|c|c|c|c|c|}
\hline $\begin{array}{l}\text { Dependent variable } \\
\text { effects on indicators }\end{array}$ & Independent variable & Unstandardized Coefficient & SE & \\
\hline Home environment & $\leftarrow$ Education & 0.174 & 0.024 & $* * *$ \\
\hline Preschool (t1) & $\leftarrow$ Education & 0.065 & 0.098 & \\
\hline Preschool (t1) & $\leftarrow$ Ethnic origin & -2.213 & 0.499 & $* * *$ \\
\hline Cognition (t1) & $\leftarrow$ Home environment & 0.463 & 0.079 & $* * *$ \\
\hline Cognition (t1) & $\leftarrow$ Education & 0.076 & 0.027 & $* *$ \\
\hline Cognition (t1) & $\leftarrow$ Age $(\mathrm{t} 1)$ & 0.165 & 0.018 & $* * *$ \\
\hline Cognition (t1) & $\leftarrow$ Preschool (t1) & 0.002 & 0.007 & \\
\hline Cognition (t2) & $\leftarrow$ Home environment & -0.049 & 0.063 & \\
\hline Cognition (t2) & $\leftarrow$ Education & 0.011 & 0.023 & \\
\hline Cognition (t2) & $\leftarrow$ Time span between & 0.107 & 0.031 & $* * *$ \\
\hline Cognition (t2) & $\leftarrow$ Cognition $(\mathrm{t} 1)$ & 0.625 & 0.061 & $* * *$ \\
\hline Cognition (t2) & $\leftarrow$ Preschool $(\mathrm{t} 1)$ & 0.013 & 0.006 & $*$ \\
\hline Magic window (t2) & $\leftarrow$ Cognition $(\mathrm{t} 2)$ & 1.207 & 0.068 & $* * *$ \\
\hline Face recognition (t2) & $\leftarrow$ Cognition $(\mathrm{t} 2)$ & 1.000 & & \\
\hline Gestalt closure (t2) & $\leftarrow$ Cognition $(\mathrm{t} 2)$ & 2.024 & 0.107 & $* * *$ \\
\hline Story telling & $\leftarrow$ Home environment & 1.000 & & \\
\hline Reading aloud & $\leftarrow$ Home environment & 1.391 & 0.181 & $* * *$ \\
\hline Playing games & $\leftarrow$ Home environment & 0.241 & 0.071 & $* * *$ \\
\hline Playing games & $\leftarrow$ Age $(\mathrm{t} 1)$ & 0.055 & 0.015 & $* * *$ \\
\hline Reading aloud & $\leftarrow$ Age $(\mathrm{t} 1)$ & 0.009 & 0.013 & \\
\hline Story telling & $\leftarrow$ Age $(\mathrm{t} 1)$ & 0.021 & 0.016 & \\
\hline Magic window (t1) & $\leftarrow$ Cognition $(\mathrm{t} 1)$ & 1.655 & 0.129 & $* * *$ \\
\hline Face recognition $(\mathrm{t} 1)$ & $\leftarrow$ Cognition $(\mathrm{t} 1)$ & 1.000 & & \\
\hline Gestalt closure (t1) & $\leftarrow$ Cognition $(\mathrm{t} 1)$ & 1.256 & 0.104 & $* * *$ \\
\hline Magic window (t2) & $\leftarrow$ Ethnic origin & -0.782 & 0.176 & $* * *$ \\
\hline Face recognition $(\mathrm{t} 2)$ & $\leftarrow$ Ethnic origin & 1.725 & 0.170 & $* * *$ \\
\hline Gestalt closure (t2) & $\leftarrow$ Ethnic origin & -0.016 & 0.256 & \\
\hline Playing games & $\leftarrow$ Ethnic origin & -0.340 & 0.122 & $* *$ \\
\hline Reading aloud & $\leftarrow$ Ethnic origin & -1.505 & 0.121 & $* * *$ \\
\hline Story telling & $\leftarrow$ Ethnic origin & -0.751 & 0.140 & $* * *$ \\
\hline Magic window (t1) & $\leftarrow$ Ethnic origin & -1.920 & 0.215 & $* * *$ \\
\hline Face recognition $(\mathrm{t} 1)$ & $\leftarrow$ Ethnic origin & 0.796 & 0.195 & $* * *$ \\
\hline Gestalt closure (t1) & $\leftarrow$ Ethnic origin & -1.133 & 0.196 & $* * *$ \\
\hline Home environment & $\leftarrow$ Education & 0.174 & 0.024 & $* * *$ \\
\hline Preschool (t1) & $\leftarrow$ Education & 0.065 & 0.098 & $* * *$ \\
\hline
\end{tabular}

*** Significant with $P \leq .001 .{ }^{* *}$ Significant with $P \leq .01$. ${ }^{*}$ Significant with $P \leq .05$.

sum it up the descriptives clearly show that the abilities of the child during wave one are connected with all other variables, especially with the education and the home environment. As expected some of the cognitive measurements are highly correlated (but far from perfect), but also education and reading have high correlation coefficients (for all correlations between these entire variables, see Table 5).

\section{Results}

Figure 2 displays the structural equation model of cognitive outcomes (t2) (for the measurement model, see Table 3).
All fit indices suggest that the empirical model fits very well. Both family and home environment have a significant influence on the cognitive outcome. However, the influence of the home environment is bigger than the direct influence of education. The standardized total effects show that the total effect of education is . 20 and the total effect of home environment is.18 (see also Table 2). This finding is due to the fact that the home environment mediates the influence of education. Since there is no mediator for the influence of the home environment, the direct effect and the total effect of the home environment are identical. It seems as if higher educated parents really are able to stimulate their children 
TABLE 5: Correlations of the variables in the model.

\begin{tabular}{|c|c|c|c|c|c|c|c|c|c|c|c|}
\hline & MW1 & FR1 & GC1 & MW2 & FR2 & GC2 & $\mathrm{H} 1$ & $\mathrm{H} 2$ & H3 & Edu & Pre \\
\hline MW1 & 1.00 & & & & & & & & & & \\
\hline FR1 & 0.32 & 1.00 & & & & & & & & & \\
\hline GC1 & 0.55 & 0.26 & 1.00 & & & & & & & & \\
\hline MW2 & 0.48 & 0.23 & 0.32 & 1.00 & & & & & & & \\
\hline FR2 & 0.08 & 0.27 & 0.10 & 0.25 & 1.00 & & & & & & \\
\hline GC2 & 0.42 & 0.23 & 0.45 & 0.49 & 0.35 & 1.00 & & & & & \\
\hline $\mathrm{H} 1$ & 0.27 & 0.11 & 0.17 & 0.17 & -0.02 & 0.10 & 1.00 & & & & \\
\hline $\mathrm{H} 2$ & 0.41 & 0.07 & 0.27 & 0.25 & -0.13 & 0.17 & 0.49 & 1.00 & & & \\
\hline $\mathrm{H} 3$ & 0.12 & 0.12 & 0.12 & 0.12 & 0.07 & 0.13 & 0.16 & 0.15 & 1.00 & & \\
\hline Edu & 0.38 & 0.00 & 0.28 & 0.25 & -0.13 & 0.15 & 0.30 & 0.53 & 0.05 & 1.00 & \\
\hline Pre & 0.18 & 0.13 & 0.18 & 0.18 & 0.10 & 0.17 & 0.09 & 0.13 & 0.08 & 0.12 & 1.00 \\
\hline
\end{tabular}

MW1: magic window (t1); FR1: face recognition (t1); GC1: gestalt closure (t1); MW2: magic window (t2); FR2: face recognition (t2); GC2: gestalt closure (t2); H1: story telling; H2: reading; H3: playing cards; Edu: years of parental education; Pre: preschool attendance.

better. This effect is even stronger than the influence of a stimulating home environment.

Figure 3 additionally controls for the cognitive achievement one year earlier, to test if the influence found in model 1 is misadjusted caused by unobserved heterogeneity (for the measurement model, see Table 4). This model fits also very well. With these variables, 42 percent of the variance of cognition ( $\mathrm{t} 2$ ) can be explained. The standardized total effect of home environment and education of the caretaker on the later cognitive outcome ( $\mathrm{t} 2$ ) of the children are similar (both about .18). However it is important to realize that the influence of both explaining variables is mediated through the cognitive abilities of the child one year before. Education directly stimulates the prior cognition ( $\mathrm{t} 1$ ) significantly, but there exists no direct effect on cognition ( $\mathrm{t} 2$ ). As assumed the prior cognition has the strongest influence on the cognition ( $\mathrm{t} 2)$. These effects might be explained by the very short time lag between these two measurements. Hence this was controlled for within the model and has a very strong and significant influence on the cognitive outcomes (t2). So the earlier cognitive abilities of the child work as a total mediator for the influence of the education of the parents. For the influence of the home environment the cognition (t1) works as a partial mediator. After controlling for earlier cognitive outcomes (t1) the direct effect of the home environment is not significant and even changes its sign.

To compare both models, Table 2 shows the standardized direct, indirect, and total effects. To test the significance of the indirect effects I used the Sobel test (for details see [41]); for the direct and total effects I used a $t$-test.

The assumptions I tested were whether the influence of education and the home environment on cognitive abilities and improvements can also be found for German preschool children. By comparing the direct effects on cognition the two models show that education and home environment have a significant influence on cognition, but the influence in model 2 is mediated through the prior abilities of the child. If one compares the direct effects on cognition (t2) in model 1 and the direct effect on cognition (t1) in model 2, the influence of home environment in both models is stronger than the influence of education. Moreover the influence of the prior outcome is even stronger than on the later cognitive outcome of the child.

While looking at the total effects, it can be seen that the influence of education on cognition ( $\mathrm{t} 2$ ) in model 1 seems to be marginally bigger than in model 2 , whereas the influence of home environment remains rather stable.

\section{Discussion}

The presented paper tests the assumption that the education of the parents and their home environment influence the cognitive outcomes and cognitive improvement of children living in Germany. The results of the analysis confirm recent international research on this topic also for the case of Germany. Reynolds and Temple [30] and Broberg et al. [31] find for the United States and Sweden that prior outcomes of the children are very important. This study shows that the same holds true for Germany. In addition the influence of the home environment seems even more crucial for earlier outcomes. These results demonstrate that it is important to control for prior outcomes. Therefore research about achievement or development should always be longitudinal to control for this. Otherwise the influence of some variables might be overestimated.

The results show that social inequality exists even in very early preschool years. Highly educated parents may stimulate their children better than low educated parents. In addition, the home environment has a strong effect on cognitive abilities. Thus, low educated parents should be requested to be active with their children, because joint activities stimulate the cognitive development of their children. In Germany it would be easy for most of the parents to go outside with their children (e.g., visit some parks which are free of charge), to read to them (e.g., books from the library) or just play with them and offer them time. There exist quite a lot of arrangements for children which are next to their living area and free of charge (e.g., parks, playgrounds, very cheap group meetings, e.g., boy scouts or playing groups). However some 
countries try to compensate for a disadvantaged household by some high-cost preschool programs. This seems to be important in those countries with an expensive child care system. In my opinion such programs would not be necessary in the case of Germany, since the kindergarten is comparatively cheap. On the other hand low educated families might have no interest in education and have in general low educational aspirations for their children.

Although the results are significant for future research and data collection, there are also some problems. Firstly, studying cognitive abilities of young children makes it difficult to have a lot of information about prior outcomes. That is one reason why the time span between both waves is rather short. With further waves of our data collection this problem would be solved. Up to that time there is no German dataset which can avoid that problem. Secondly, the measurement of the home environment is very unilateral. We have no information about the quality of materials at home or the quality of the interaction between the caretaker and his/her child. These variables might be necessary if the goal was to explain the influence of the home environment on children's outcomes, but this is not the focus of the present study. However the measurement of activities might be correlated with the cognitive abilities of the children in that way that parents only read aloud to children with a minimum of cognitive abilities. In additional analysis I could show that the impact of activities depends on the social background of the parents and less on the abilities of the child. This should be comprehensible, since the considered activities (with the exception of card playing) should be rather independent of cognitive abilities and age. Thirdly, there exist some more important covariates, which are not considered in the shown analysis because of data restrictions. One potential important issue is the cognitive abilities of the parents, and also the number of children in the family or other economic aspects like income, parental hours of work, and so forth. Further analysis and datasets with higher number of observations are necessary to test all of this simultaneously. Within a bigger dataset also some interesting questions about the influence of the gender of the caretaker could also be analysed. The presented study mainly shows the influence of mothers on their children's cognitive abilities.

A further interesting future research topic is ethnic differences within this framework. There already exist some research showing that child-parent-interactions are different between immigrants and natives. I would assume that there might be some cultural differences between Turkish and German activities. However this is a large new topic and should be content of further research.

In sum, longitudinal data is important, so that the determinants of developmental outcomes can be considered under control of prior abilities. Obviously development and/or achievement is connected with earlier development/achievement of each individual. Therefore prior outcomes work as varying fundaments and should be controlled. However, education and the home environment are very important factors both for cognitive outcomes and improvements.

\section{Appendix}

See Tables 3, 4, and 5 .

\section{Acknowledgments}

The author would like to thank the German Research Foundation for their funding of the project and all participating parents and children (ES 41/19-1).

\section{References}

[1] N. Biedinger and O. Klein, "Der Einfluss der sozialen Herkunft und des kulturellen Kapitals auf die Häufigkeit entwicklungsfördernder Eltern-Kind-Aktivitäten," Diskurs Kindheitsund Jugendforschung, vol. 5, no. 2, pp. 195-208, 2010.

[2] O. Klein and N. Biedinger, "Determinanten elterlicher Aktivitäten mit Vorschulkindern. Der Einfluss von Bildungsaspirationen und kulturellem Kapital," Mannheimer Zentrum für Europäische Sozialforschung (MZES) Arbeitspapier: 121, 2009.

[3] N. Biedinger, "Early ethnic inequality: the influence of social background and parental involvement on preschool children's cognitive ability in Germany," Child Indicators Research, vol. 3, no. 1, pp. 11-28, 2010.

[4] N. Biedinger, "Der einfluss von elterlichen investitionen auf die entwicklung deutscher und und türkischen Kindern," Berliner Journal für Soziologie, vol. 19, no. 2, pp. 268-294, 2009.

[5] D. M. Fergusson, L. J. Horwood, and J. M. Boden, "The transmission of social inequality: examination of the linkages between family socioeconomic status in childhood and educational achievement in young adulthood," Research in Social Stratification and Mobility, vol. 26, no. 3, pp. 277-295, 2008.

[6] P. Garrett, N. Ng'andu, and J. Ferron, "Poverty experiences of young children and the quality of their home environments," Child Development, vol. 65, no. 2, pp. 331-345, 1994.

[7] J. Ermisch, "Origins of social immobility and inequality: parenting and early child development," National Institute Economic Review, vol. 205, no. 1, pp. 62-71, 2008.

[8] L. Feinstein, "Inequality in the early cognitive development of British children in the 1970 cohort," Economica, vol. 70, no. 277, pp. 73-97, 2003.

[9] L. Feinstein, "Very early evidence: how early can we predict future educational achievement?" Cenrepiece, vol. 8, pp. 2430, 2003.

[10] A. George, K. Hansen, and I. Schoon, "Millennium Cohort Study. Cognitive Development," 2007, http://www.cls.ioe.ac. uk/downloads/1Cognitive\%20AMENDED\%20230707.pdf.

[11] R. H. Bradley and R. F. Corwyn, "Age and ethnic variations in family process mediators of SES. S.," in Socioeconomic Status, Parenting, and Child Development, M. H. Bornstein and R. H. Bradley, Eds., pp. 161-188, Lawrence Erlbaum Associates, Mahwah, NJ, USA, 2003.

[12] L. Craig, "Parental education, time in paid work and time with children: an Australian time-diary analysis," British Journal of Sociology, vol. 57, no. 4, pp. 553-575, 2006.

[13] J. Brooks-Gunn, W. J. Han, and J. Waldfogel, "Maternal employment and child cognitive outcomes in the first three years of life: the NICHD study of early child care," Child Development, vol. 73, no. 4, pp. 1052-1072, 2002. 
[14] U. Schmidt-Denter, "Vorschulische Förderung," in Entwicklungspsychologie, R. Oerter and L. Montada, Eds., pp. 976-982, Beltz, Weinheim, Germany, 1995.

[15] B. Wolf, Zuwendung und Anregung. Lernumweltforschung zur Sprachentwicklung im Elternhaus und Kindergarten, Deutscher Studien, Weinheim, Germany, 1987.

[16] G. Farkas and K. Beron, "The detailed age trajectory of oral vocabulary knowledge: differences by class and race," Social Science Research, vol. 33, no. 3, pp. 464-497, 2004.

[17] T. Luster and E. Dubow, "Home environment and maternal intelligence as predictors of verbal intelligence: a comparison of preschool and school-age children," Merrill-Palmer Quarterly, vol. 38, no. 2, pp. 151-175, 1992.

[18] K. L. Denton, L. M. Reaney, and J. West, "Home educational activities, literacy resources and Kindergartners' reading knowledge and skills," in Papers from the Early Childhood Longitudinal Studies Program Presented at the 2001 AERA and SRCD Meetings, J. West, Ed., NCES, Washington, DC, USA, 2001.

[19] R. Haveman and B. Wolfe, Succeeding Generations: On the Effects of Investments in Children, Russell Sage, New York, NY, USA, 1994.

[20] H. Schöler, P. Hasselbach, P. Schäfer, A. Dressler, and H. Engler-Thümmel, "Zur Wirksamkeit von Massnahmen zur Förderung der sprachlichen Fähigkeiten in der Vorschule Mannheim," 2005), http://www.ph-heidelberg.de/ $\mathrm{wp} / \mathrm{schoeler/datein/nr20.pdf.}$

[21] K. A. Espy, V. J. Molfese, and L. F. DiLalla, "Effects of environmental measures on intelligence in young children: growth curve modeling of longitudinal data," Merrill-Palmer Quarterly, vol. 47, no. 1, pp. 42-73, 2001.

[22] L. M. Anderson, C. Shinn, M. T. Fullilove et al., "The effectiveness of early childhood development programs: a systematic review," American Journal of Preventive Medicine, vol. 24, no. 3, pp. 32-46, 2003.

[23] J. Currie, "Early childhood education programs," Journal of Economic Perspectives, vol. 15, no. 2, pp. 213-238, 2001.

[24] K. A. Magnuson, M. K. Meyers, C. J. Ruhm, and J. Waldfogel, "Inequality in preschool education and school readiness," American Educational Research Journal, vol. 41, no. 1, pp. 115$157,2004$.

[25] N. Forget-Dubois, G. Dionne, J. P. Lemelin, D. Pérusse, R. E. Tremblay, and M. Boivin, "Early child language mediates the relation between home environment and school readiness," Child Development, vol. 80, no. 3, pp. 736-749, 2009.

[26] E. C. Melhuish, M. B. Phan, K. Sylva, P. Sammons, I. SirajBlatchford, and B. Taggart, "Effects of the home learning environment and preschool center experience upon literacy and numeracy development in early primary school," Journal of Social Issues, vol. 64, no. 1, pp. 95-114, 2008.

[27] K. M. La Paro and R. C. Pianta, "Predicting children's competence in the early school years: a meta-analytic review," Review of Educational Research, vol. 70, no. 4, pp. 443-484, 2000.

[28] S. Normandeau and F. Guay, "Preschool behavior and firstgrade school achievement: the mediational role of cognitive self-control," Journal of Educational Psychology, vol. 90, no. 1, pp. 111-121, 1998.

[29] A. J. Reynolds, "A structural model of first-grade outcomes for an urban, low socioeconomic status, minority population," Journal of Educational Psychology, vol. 81, no. 4, pp. 594-603, 1989.
[30] A. J. Reynolds and J. A. Temple, "Extended early childhood intervention and school achievement: age thirteen findings from the Chicago longitudinal study," Child Development, vol. 69, no. 1, pp. 231-246, 1998.

[31] A. G. Broberg, H. Wessels, M. E. Lamb, and C. P. Hwang, "Effects of day care on the development of cognitive abilities in 8-year-olds: a longitudinal study," Developmental Psychology, vol. 33, no. 1, pp. 62-69, 1997.

[32] W. J. J. Yeung and K. M. Pfeiffer, "The black-white test score gap and early home environment," Social Science Research, vol. 38, no. 2, pp. 412-437, 2009.

[33] A. S. Kaufman and N. L. Kaufman, Kaufman Assessment Battery for Children K-ABC, Swets Test Service, Frankfurt, Germany, 1994.

[34] P. Melchers and U. Preuss, K-ABC. Kaufman-Assessment Battery for Children. Deutschsprachige Fassung. Interpretationshandbuch, Swets \& Zeitlinger, Frankfurt, Germany, 2003.

[35] J. L. Arbuckle, Amos 6.0 User's Guide, SmallWaters, Chicago, Ill, USA, 2005.

[36] R. M. Baron and D. A. Kenny, "The moderator-mediator variable distinction in social psychological research: conceptual, strategic, and statistical considerations," Journal of Personality and Social Psychology, vol. 51, no. 6, pp. 1173-1182, 1986.

[37] R. E. Schumacker and R. G. Lomax, Beginner's Guide to Structural Equation Modeling, Erlbaum, Mahwah, NJ, USA, 2004.

[38] N. J. Blunch, Introduction to Structural Equation Modelling Using SPSS and AMOS, Sage, London, UK, 2008.

[39] R. P. McDonald and M. H. R. Ho, "Principles and practice in reporting structural equation analyses," Psychological Methods, vol. 7, no. 1, pp. 64-82, 2002.

[40] J. Reinecke, Strukturgleichungsmodelle in den Sozialwissenschaften, Oldenbourg Wissenschaftsverlag, München, Germany, 2005.

[41] M. E. Sobel, "Asymptotic confidence intervals for indirect effects in structural equation models," Sociological Methodology, vol. 13, pp. 290-312, 1982. 


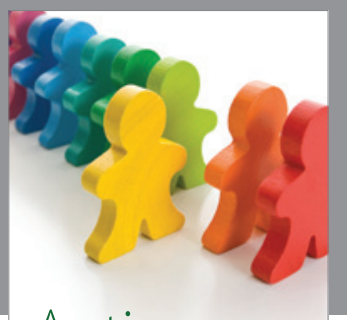

Autism

Research and Treatment
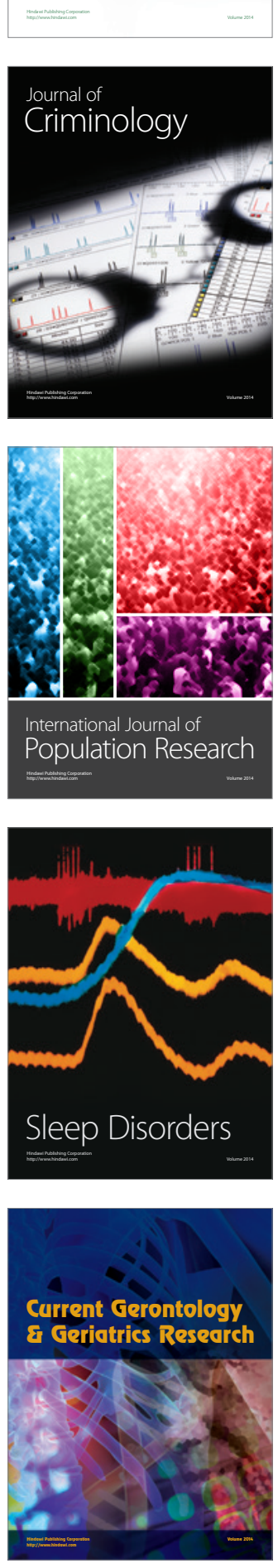
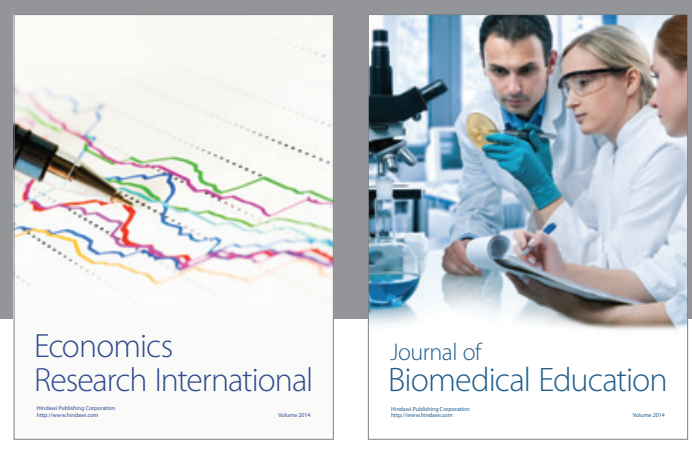

Journal of

Biomedical Education

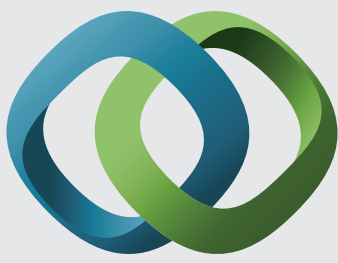

\section{Hindawi}

Submit your manuscripts at

http://www.hindawi.com
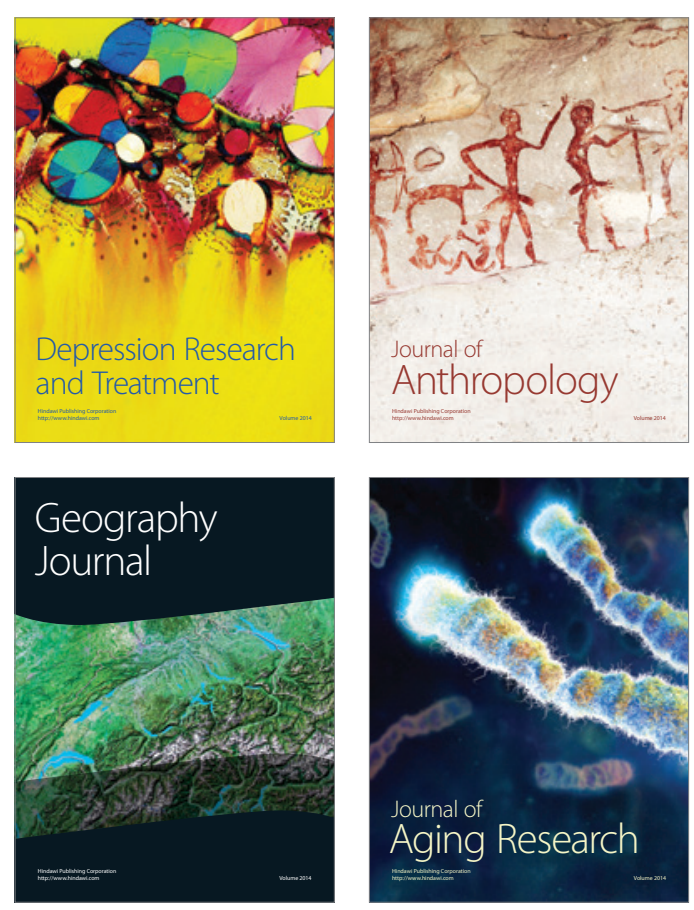

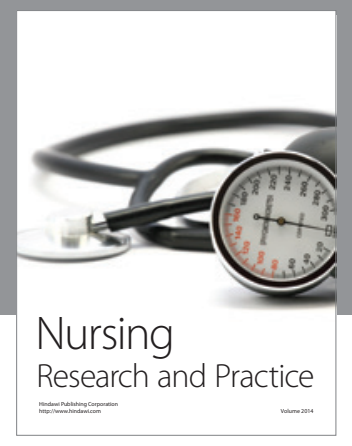

Nursing

Research and Practice

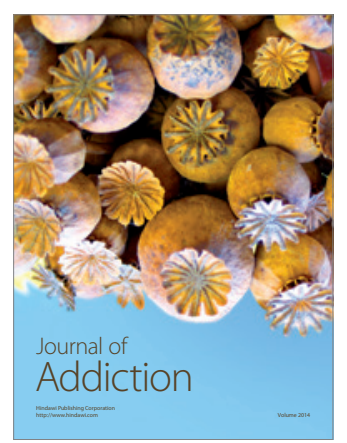

Child Development

Research

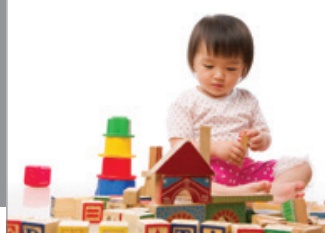

迥
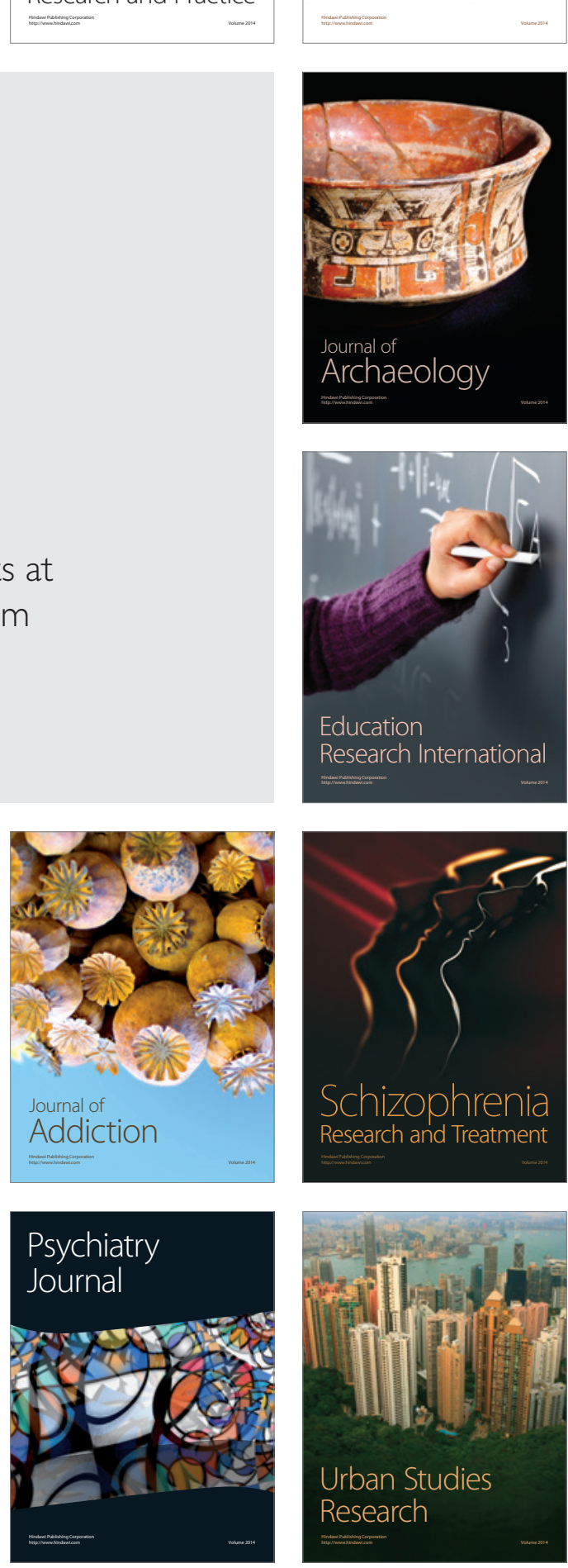